\title{
A Study on Pediatric Nurses' Pain Management Knowledge and Practices in Turkey
}

\section{(1) Ayşegül Şimşek¹, (1D Duygu Gözen²}

1istinye University Faculty of Health Sciences, Department of Midwifery, İstanbul, Turkey

${ }^{2}$ İstanbul University-Cerrahpaşa, Florence Nightingale Faculty of Nursing, Department of Child Health and Diseases Nursing, İstanbul, Turkey

Cite this article as: Şimşek A, Gözen D. A Study on Pediatric Nurses' Pain Management Knowledge and Practices in Turkey. Trends in Pediatrics 2021;2(4):159-164

\begin{abstract}
Objective: With a child's less developed ability to express oneself when compared to adults, it is a more challenging task to manage pain in children. Nurses, as those who spend the most time with patients, need to have sufficient knowledge about assessing and managing pain in children. The aim of this study is to determine the knowledge and pediatric practices of nurses working in pediatric clinics on pain management in children.

Methods: This descriptive study was completed with 134 nurses. Study data were captured through using a questionnaire drafted, and rearranged in line with specialist advice, by the researchers. Data were electronically evaluated with percentage, Kruskal-Wallis $\mathrm{H}$ and Mann-Whitney U tests using analysis system.

Results: It was determined that $81.3 \%$ of nurses had not been trained on pain management in children. It was established that nurses preferred pharmacological methods to non-pharmacological, that $54.5 \%$ of them used a combination of pharmacological and non-pharmacological methods to relieve pain in children, and that $16.4 \%$ mentioned difficulty in pain management due to lack of time. Nurses' knowledge of pain management was found to be slightly above the average (maximum 22 points; median \pm standard deviation=16.50 \pm 2.74 ; minimum-maximum: 9-21).

Conclusion: The study established that nurses' level of knowledge about pain management was inadequate, that nurses encountered various challenges in pain management arising from the workplace setting, and that rate of use of non-pharmacological pain treatment methods, an independent function of nursing, is significantly low.
\end{abstract}

Keywords: Children, non-pharmacological treatment, pain management

\section{INTRODUCTION}

The Taxonomy Committee of the International Association for the Study of Pain (IASP) defines pain as "an unpleasant sensory and emotional experience associated with actual or potential tissue damage or described in terms of such damage" ${ }^{1-3}$ Assessment of pain takes an individual's age and physical, psychological, social, and environmental factors into consideration. ${ }^{2,4}$ The major problem in the assessment of pain in children is an imprecise verbal account of pain experienced by children due to inadequate language development. ${ }^{3}$ Untreated pain leads to biological, psychological, social, developmental, and behavioral problems in children. ${ }^{4}$ The first step in pain management is clarifying the level, severity, and location of the pain. Many pain scales [visual analog scales (VAS), "Face, Legs, Activity, Cry, Consolability", Wong-Baker] are applied to obtain the presence of pain. These scales are used according to age, responsiveness, medical diagnosis, and treatment of the child and can be effectively used to make pain concrete. After defining the pain level with scales, the next step is to relieve the pain or reduce its severity. At this stage, pharmacological and nonpharmacological methods can be used alone or in combination. While analgesics are the most preferred pharmacological method,

D. Gözen: 0000-0001-9272-3561

Address for Correspondence: Ayşegül Şimşek

Istinye University Faculty of Health Sciences, Department of Midwifery, İstanbul, Turkey

E-mail: aysegul.simsek@istinye.edu.tr ORCID-ID: orcid.org/0000-0002-2166-1778

Received: 30.07.2021 Accepted: 17.09.2021 Publication date: 04.01.2022

${ }^{\circ}$ Copyright 2021 by the Aydın Pediatric Society / Trends in Pediatrics published by Galenos Publishing House.

Licenced by Creative Commons Attribution 4.0 International (CC BY) 
many non-pharmacological methods including distraction, massage, and oral sucrose can also be preferred. ${ }^{3,5,6}$

Effective pain management takes correct information, attitude, appraisal, and therapeutic intervention skills. ${ }^{7}$ There are several aspects differentiating nurses in pain management from other medical staff members: prolonged interaction with the patient; early awareness of pain; observation of patient's previous pain experience and methods to cope with pain; implementation of planned treatment and observation of effects and results of such treatment; guidance and support to a family with an empathetic approach. ${ }^{2,8}$

While pain is sometimes an indicator of an existing problem, it sometimes becomes an aggravating factor for this problem. Therefore, it should be detected, evaluated, and remedied as early as possible. Relieving the pain of a child is one of the most familiar issues for pediatric nurses. Nurses should know every stage of pain management within the scope of care and should relieve pain. When the literature is evaluated, it is seen that there are many studies on the knowledge of pain management of nurses and that these studies examine the pain infornation of nurses and the methods they use to relieve pain..$^{2,3,9,10}$ Despite many studies, there is still insufficient information on pain management, and the origin of these deficiencies is wondered..$^{1,3,8,9}$ In the light of this information, we aimed to determine the knowledge and practices of nurses working in pediatric clinics on pain management in children.

\section{Study Questions}

What is the level of knowledge of pediatric nurses about pain management in children?

What is the rate of pediatric nurses knowing and using pain assessment tools in children?

Which methods do pediatric nurses use in children's pain management?

\section{MATERIALS and METHODS}

\section{Study Design}

This descriptive study was conducted in all private, state, and university hospitals in a city.

\section{Participants}

The research population consisted of 184 nurses working in pediatric clinics in all hospitals in a city. In the sample calculation, it was concluded that 123 nurses should be reached with a sampling error of \pm 0.05 and a $95 \%$ confidence interval. One nurse could not participate in the study because she was on unpaid leave, and one nurse was in the military. The study was completed with 134 nurses who met the inclusion criteria.

The study was carried out in one university hospital, one maternity and children's hospital, one training and research hospital, eight state hospitals, and four private hospitals. The participants of this study were pediatric nurses working in pediatrics, pediatric surgery, pediatric emergency, pediatric intensive care, and neonatal intensive care units of these hospitals.

\section{Data Collection Tools}

In the collection of data, a data collection form consisting of, ${ }^{1,10-}$ ${ }^{14} 62$ open and closed-ended questions prepared in line with the literature was used. The questionnaire consisted of 3 sections, the first of which contained 16 questions to solicit information on nurses' socio-demographic characteristics, professional status, and experience. The second of which contained 24 questions concerning nurses' practices aiming to manage pain and factors affecting these practices. The third section consisted of 22 questions prepared to assess nurses' level of knowledge about pain management. This section was sent to 5 specialists in pediatric nursing in terms of content and relevance. An evaluation form, in which the appropriateness of each question item, and the opinions and comments could be included, was used to obtain expert opinions about the applicability of the survey questions. The questions were revised in line with the information obtained. Nurses giving correct answers to all the questions in this section scored 22. Data were collected through interviews conducted by the researcher with nurses in person.

\section{Statistical Analysis}

Data gathered in the study were analyzed using Statistical Package for the Social Sciences version 18 software program (IBM Company). While the median and standard deviation values were calculated in the analysis of continuous data, numbers and percentages were calculated in the analysis of categorical data such as age and gender. In the comparison of pain knowledge score and descriptive information, non-parametric tests were used by looking at the normality distribution. Mann-Whitney $U$ test was performed to compare the pediatric willingness to work in the clinic and institution variables with pain management knowledge. The Kruskal-Wallis test was used to compare the working style and hours, and the knowledge of pain management of the nurses. Findings were evaluated at a confidence interval of $95 \%$ and a significance level of $p<0.05$.

\section{Ethical Considerations}

Before the study, written approval was obtained from the provincial health directorate and the directorates of the hospitals where the study would be conducted, and the local ethics committee approval was obtained from Kocaeli University Clinical Research Ethic Committee (approval number: KAEK 12/1, date: 20.10.2011). Because only one hospital had a local ethics committee among all hospitals included in the study, ethics committee approval was obtained from this committee. Before the study, the participants were informed about the study, and the written and verbal consents were obtained. 


\section{RESULTS}

Information on the introductry characteristics of nurses is given in Table 1. It was found that $51.5 \%$ of the nurses were undergraduate graduates, most of the nurses had less than 5 years of nursing experience and the duration of experience in the pediatric clinic was less than 1 year. While $84.3 \%$ of the nurses worked in shifts, $74.6 \%$ stated that they did not choose to work in the pediatric clinic, and $68.7 \%$ were satisfied with working in the pediatric clinic. However, it was determined that more than half of them did not follow professional publications and did not attend scientific meetings.

It was defined that $18.7 \%$ of the nurses had previously received training on pain management in children, and about half of them did not record the presence of pain in the patient file. Information on nurses' knowledge and use of the pediatric pain scale is given in Table 2. It was found that 33.3\% used distraction, $28.3 \%$ used hot/ cold dressing, and $11.7 \%$ used massage as a non-pharmacological method. Relaxation techniques, kangaroo care, repositioning, landscaping, pacifier use, and individualized care were other methods used. Nurses reported that $16.4 \%$ did not practice non-pharmacological methods due to lack of time, $9.6 \%$ due to communication problems with the patient and their relatives, and $9 \%$ due to communication problems with the team.Nearly half of the nurses reported that they needed information on pain assessment and management and $13.4 \%$ on non-pharmacological methods. The median value of the pain scores of the nurses was $16 \pm 2.74$ [minimum (min)-maximum ( $\max$ ); 9-21] points (Table 3 ).

While $89.5 \%$ of the nurses reported that they did not know that pain is a vital sign; $29 \%$ stated that they accepted the presence of pain if the child and their parents reported pain. While $28 \%$ reported that newborns/infants perceived pain, $40 \%$ stated that the child's pain is not always a symptom of the disease. When the knowledge levels of nurses on pain management were evaluated, it was determined that the knowledge scores of the

\begin{tabular}{|l|l|l|l|}
\hline Table 1. Socio-demographic characteristics of nurses $(\mathbf{n}=134)$ \\
\hline Characteristics & Groups & $\mathbf{n}$ & $\%$ \\
\hline \multirow{4}{*}{ Age } & $20-24$ years & 64 & 47.8 \\
\cline { 2 - 4 } & $25-29$ years & 36 & 26.8 \\
\cline { 2 - 4 } & $30-34$ years & 23 & 17.2 \\
\cline { 2 - 4 } & 35 years and older & 11 & 8.2 \\
\hline \multirow{3}{*}{ Mender } & Male & 6 & 4.5 \\
\cline { 2 - 4 } & Female & 128 & 95.5 \\
\hline \multirow{3}{*}{ Having a child } & Married & 69 & 51.5 \\
\cline { 2 - 4 } & Single & 65 & 48.5 \\
\hline \multirow{4}{*}{ Level of education } & Yes & 45 & 33.6 \\
\cline { 2 - 4 } & No & 89 & 66.4 \\
\cline { 2 - 4 } & High school & 38 & 28.4 \\
\cline { 2 - 4 } & Undergraduate & 69 & 20.1 \\
\hline Total & & 134 & 100 \\
\hline
\end{tabular}

nurses working in university [16.70 \pm 1.64 (min-max; 13-20)] and state hospitals [15.47 \pm 3.19 (min-max; 9-21)] were higher than the nurses working in private hospitals [16.12 \pm 2.94 (min$\max ; 11-21)]$, and the difference was statistically significant $(p=0.03)$. When the nurses' work patterns and pain management knowledge scores were compared, it was found that the scores of those who worked during the daytime were higher, but there was no statistical difference between them $(p>0.05)$. While the pain management knowledge scores of nurses who worked 40 48 hours a week [16.72 \pm 2.16 (min-max; 11-21)] were higher than those who worked for 48 hours and above a week [15.39 \pm 3.07 (min-max; 9-21)], a statistical difference was found between working time and pain management knowledge scores $(p=0.01)$.

\begin{tabular}{|c|c|c|c|}
\hline \multicolumn{2}{|l|}{ Characteristics } & \multirow{2}{*}{$\begin{array}{l}n \\
56\end{array}$} & \multirow{2}{*}{$\begin{array}{l}\% \\
41.8\end{array}$} \\
\hline Awareness of & Yes & & \\
\hline $\begin{array}{l}\text { any assessment } \\
\text { scale }\end{array}$ & No & 78 & 58.2 \\
\hline \multirow{2}{*}{$\begin{array}{l}\text { Known } \\
\text { assessment } \\
\text { scales* }\end{array}$} & VAS & 24 & 18 \\
\hline & Wong-Baker & 32 & 23.8 \\
\hline \multirow{2}{*}{$\begin{array}{l}\text { Use of any } \\
\text { assessment scale } \\
\text { at the clinic }\end{array}$} & Yes & 40 & 29.8 \\
\hline & No & 94 & 70.2 \\
\hline \multirow{3}{*}{$\begin{array}{l}\text { Assessment } \\
\text { scales used at } \\
\text { the clinic* }\end{array}$} & VAS & 7 & 5.2 \\
\hline & FLACC & 3 & 2.2 \\
\hline & Wong-Baker & 30 & 22.4 \\
\hline \multirow{2}{*}{$\begin{array}{l}\text { Personal use of } \\
\text { any assessment } \\
\text { scale }\end{array}$} & Yes & 19 & 14.2 \\
\hline & No & 115 & 85.8 \\
\hline \multirow{2}{*}{$\begin{array}{l}\text { Assessment } \\
\text { scales personally } \\
\text { used* }\end{array}$} & VAS & 3 & 2.2 \\
\hline & Wong-Baker & 16 & 12 \\
\hline \multirow{3}{*}{$\begin{array}{l}\text { Interventions of } \\
\text { nurses to relieve } \\
\text { pain }\end{array}$} & Pharmacological practices & 48 & 35.8 \\
\hline & Non-pharmacological practices & 13 & 9.7 \\
\hline & $\begin{array}{l}\text { Pharmacological and non- } \\
\text { pharmacological practices }\end{array}$ & 73 & 54.5 \\
\hline \multicolumn{4}{|c|}{ *Those refraining from answering relevant questions were not considered } \\
\hline
\end{tabular}

Table 3. Distribution of nurses' median scores of pain management knowledge

\begin{tabular}{|l|l|l|l|l|}
\hline \multirow{2}{*}{$\begin{array}{l}\text { Level of knowledge about } \\
\text { pain management }\end{array}$} & \multirow{2}{*}{$\begin{array}{l}\text { Number } \\
\text { of items }\end{array}$} & \multicolumn{2}{l|}{ Correct } & \multirow{2}{*}{ Min - Max } \\
\cline { 3 - 5 } & 6 & 14 & 10.4 & $1-6$ \\
\hline General pain knowledge & 6 & 11 & 8.2 & $4-12$ \\
\hline Pain assessment & 12 & 26 & 19.4 & $0-4$ \\
\hline Pain treatment & 4 & 51 & 38 & $9-21$ \\
\hline Total & 22 & \multicolumn{4}{|l}{} \\
\hline Min: Minimum, Max: Maximum & &
\end{tabular}


When the nurses' willingness to work in the pediatric clinic and their pain management knowledge scores were examined, it was determined that the knowledge scores of those who wanted to work in the pediatric clinic were higher and there was no statistical difference between them ( $p>0.05$ ) (Table 4).

\section{DISCUSSION}

Effective and comprehensive implementation of pain management can be achieved by adding the experience of nurses in the clinics they work after graduation, on top of the theoretical knowledge they received during their undergraduate education. No matter how comprehensive the theoretical knowledge is, the place of clinical skills and postgraduate scientific studies and courses is undeniable. In line with the information obtained from this study and the literature, it is concluded that pain management in school and after working life is not emphasized enough. ${ }^{7,10,11,15-18}$

Besides the factors related to nurses, the institution, institution policies, the satisfaction of the nurses from the clinics they work, the communication within the team, the working order, and the weekly working hours can also affect pain management in clinics. ${ }^{1,6,19}$

To increase knowledge and be aware of current practices during the clinical study in pain management, the continuation of scientific publications, meetings, and training should be ensured. In our study, it was seen that a small part of the nurses received pain management training, and in line with the other data obtained, it was suggested that the working population could not provide a comprehensive and effective management process in pain management.

When pain management is considered, detection of pain presence, determination of pain level, relieving pain with pharmacological and non-pharmacological methods, and recording pain by regular follow-up are the most prominent steps in pain management. ${ }^{3,8,13}$

Accepting the presence of pain and determining the level of pain are the main principles in pain management. Scales are used to determine the level of pain. ${ }^{20}$ While $67.9 \%$ of nurses considered themselves competent in pain management, when asked if they knew of a pain assessment scale, $58.2 \%$ answered negatively. Pain assessment scales provide nurses with convenience in appraising pain. ${ }^{3,14}$ It was found that very few of the nurses knew and used pain assessment scales in our study. The procedures adopted by the institution also play a role in the use of pain assessment scales as well as the personal approach of nurses. Study findings led us to the conclusion that nurses neglected to use pain assessment scales, and that usage of scales was not widespread across clinics (29.8\%) or enforced through protocols. One study reported that pain management should be included in in-hospital procedures and standard pain management protocols should be established. ${ }^{3}$ Thus, the pain will become a visible and tangible notion. ${ }^{21}$

As a result of numerous studies conducted, several pain assessments scales have been developed taking the age of the patient and involved clinic into consideration and made available for use after necessary validity/reliability tests. ${ }^{4,5,10}$ However, the fact that enrolled nurses were aware of only two pain assessment scales (VAS and Wong-Baker) was an indication of the education gap or difficulties experienced by nurses in accessing conducted studies. The best-known tools for assessing pain are WongBaker and VAS. These scales have been used for many years and are reliable, effective, and easy-to-use scales. Similarly, several studies conducted in the country also reported that nurses were not using any pain assessment scales. ${ }^{6,21,10}$ In the present study, we interviewed with nurses from all hospital groups (private, state, university), and the level of knowledge of nurses working at university hospitals about pain management was found to be significantly higher than that of nurses working at other hospitals. This result, like the Finnish example, ${ }^{2}$ is the expected outgrowth of the fact that nurses working at university hospitals are more knowledgeable than nurses from other hospitals as university hospitals in the country are primarily research- and educationoriented hospitals. In the studies that the knowledge of nursing students about pain management and non-pharmacological practices was examined, it was reported that their knowledge level

Table 4. Comparison of nurses' working conditions and their level of knowledge

\begin{tabular}{|c|c|c|c|c|}
\hline \multirow{2}{*}{\multicolumn{2}{|c|}{ Working conditions }} & \multirow{2}{*}{\begin{tabular}{|l|} 
n (\%) \\
$49(36.6)$ \\
\end{tabular}} & \multicolumn{2}{|c|}{$\begin{array}{l}\text { Level of knowledge about pain } \\
\text { management }\end{array}$} \\
\hline & & & Min - Max & Test value/p \\
\hline Institution & $\begin{array}{l}\text { University hospital } \\
\text { State hospital } \\
\text { Private hospital }\end{array}$ & $\begin{array}{l}49(36.6) \\
69(51.5) \\
16(11.9)\end{array}$ & $\begin{array}{l}13-20 \\
9-21 \\
11-20\end{array}$ & $3,429 * / 0.03$ \\
\hline Working order & $\begin{array}{l}\text { Consistently daytime } \\
\text { By shifts }\end{array}$ & $\begin{array}{l}21(15.7) \\
113(84.3)\end{array}$ & $\begin{array}{l}12-20 \\
9-21\end{array}$ & $1.400 * / 2.37$ \\
\hline Working hours (/a week) & $\begin{array}{l}40 \text { to } 48 \text { hours } \\
48 \text { hours and above }\end{array}$ & $\begin{array}{l}65(48.5) \\
69(51.5)\end{array}$ & $\begin{array}{l}11-21 \\
9-21\end{array}$ & $-2,569 * * / 0.01$ \\
\hline $\begin{array}{l}\text { Whether employment with pediatric clinic } \\
\text { is voluntary }\end{array}$ & $\begin{array}{l}\text { Yes } \\
\text { No }\end{array}$ & $\begin{array}{l}34(25.4) \\
100(74.6)\end{array}$ & $\begin{array}{l}12-21 \\
9-21\end{array}$ & $-1.316^{* *} / 0.188$ \\
\hline
\end{tabular}


was not sufficient. ${ }^{19}$ This result also confirmed that neither nursing students nor graduate nurses were sufficiently knowledgeable about the implementation of non-pharmacological interventions or knew that interventions which they implemented might be considered as non-pharmacological interventions similar to the results of the present study. When we look at the studies on pain management with nurses in the literature, although there are many studies in which pain is addressed, it is seen that the level of knowledge is still not sufficient. ${ }^{3,11,13}$ In many studies conducted, non-pharmacological methods were reported to be effective in mitigating pain. ${ }^{15,16,21}$ In our study, and other studies, it was seen that nurses knew pharmacological practices. ${ }^{2,3,8,9}$ In our study, it was found that nurses were aware of non-pharmacological methods which had independent functions in pain management. Nurses cannot carry out non-pharmacological practices effectively because of personal factors and working conditions. The findings we obtained were similar to the literature. ${ }^{6,16}$

While the clinical use of pain as the fifth vital sign was included in the literature, it was seen in our study that the number of nurses who accepted pain as a vital sign was low. Although the frequency of studies on this subject increased, it was seen that nurses still did not know the routine evaluation of pain. ${ }^{21}$ In our study, the pain scores of the nurses were found to be above the median value, while it was reported to be in average values in other studies. ${ }^{6,20}$ This result might be a consequence of the facilitation of access by nurses to information in the period from the former study to date and frequent emphasis put on pain in recent years. Elimination of pain is a human right, and the pain of a patient should be relieved or mitigated to an acceptable level, regardless of the age of the patient. Especially, children should not be expected or required to endure pain..$^{1,3,6,10}$ The intermediate knowledge level of nurses about the treatment of pain in the present study leads us to the conclusion that the knowledge deficiency of nurses is not only about assessment but also about the treatment of pain in children.

\section{Study Limitations}

The main limitation of the research was that the population and sample of the research are only pediatric nurses working in hospitals located in a city constituted the population and sample of the research. The findings of the study were limited to the scope of the data collection form used and the answers given by the nurses in the sample group.

\section{CONCLUSION}

It was concluded that the knowledge level of nurses on pain management was moderate. It was determined that even if the nurses did not receive training on pain management, they used pain assessment scales and non-pharmacological applications to a small extent in the units they worked. It was concluded that the biggest obstacle to the nurses' inability to concentrate on pain management was the lack of time. Nurses should provide care for children experiencing pain based on scientific facts. To active this, we concluded that pain should be cited among routine vital signs in hospital protocols, and that nurses' knowledge of pain management should be consolidated through training.

\section{Ethics}

Ethics Committee Approval: The local ethics committee approval was obtained from Kocaeli University Clinical Research Ethic Committee (approval number: KAEK 12/1, date: 20.10.2011).

Peer-reviewed: Externally and internally peer-reviewed.

\section{Authorship Contributions}

Surgical and Medical Practices: A.Ş., D.G., Concept: A.Ş., D.G., Design: A.Ş., D.G., Data Collection or Processing: A.S., Analysis or Interpretation: A.Ş., Literature Search: A.Ş., D.G., Writing: A.Ş., D.G.

Conflict of Interest: The authors declared no potential conflicts of interest with respect to the research, authorship, and/or publication of this article.

Funding: The authors received no financial support for the research, authorship, and/or publication of this article.

\section{REFERENCES}

1. Manworren RC, Stinson J. Pediatric pain measurement, assessment, and evaluation. Semin Pediatr Neurol. 2016;23:189-200.

2. Peirce D, Brown J, Corkish V, Lane M, Wilson S. Instrument validation process: a case study using the Paediatric Pain Knowledge and Attitudes Questionnaire. J Clin Nurs. 2016;25:1566-75.

3. Wuni A, Salia SM, Ibrahim MM, et al. Evaluating knowledge, practices, and barriers of paediatric pain management among nurses in a tertiary health facility in the northern region of ghana: a descriptive cross-sectional study. Pain Res Manag. 2020;2020:8846599.

4. Akkaya A. The effect of using pacifier and dextrose pacifier on pain reduction during orogastric tube placement in newborns. Unpublished master's thesis. Uludağ University Institute of Health Sciences. 2020, Bursa

5. Akpolat R, Şişman H, Alptekin D, Gökçe E, Gezer D, Arslan S. Evaluation of approaches to pain after surgery. Cukurova Med J. 2021;46:670-6.

6. Kodama Y, Fukahori H, Tse M, Yamamoto-Mitani N. Pain Prevalence, Pain Management, and the Need for Pain Education in Healthcare Undergraduates. Pain Manag Nurs. 2021;22:408-13.

7. Akdemir N, Akyar I, Görgülü Ü. Approaches of nurses to the pain problem of patients hospitalized in physical therapy and rehabilitation clinics or admitted to outpatient clinics. Turk J Phys Med Rehab. 2008;54:157-63.

8. Hroch J, Van Den Kerkhof EG, Sawhney M, Sears N Gedcke-Kerr L. Knowledge and Attitudes about Pain Management among Canadian Nursing Students. Pain Manag Nurs. 2019;20:382-9.

9. Staveski SL, Boulanger K, Erman L, et al. The Impact of Massage and Reading on Children's Pain and Anxiety after Cardiovascular Surgery: A Pilot Study. Pediatr Crit Care. 2018;19:725-32.

10. Peng N, Lao AH, Chen $\mathrm{C}$, et al. Knowledge and attitudes of pediatric clinicians regarding pediatric pain management. J Spec Pediatr Nurs. 2020;25:e12302.

11. Al-Taweel D, Awad A. Development, and validation of medication assessment tools to evaluate prescribing adherence to evidence-based guidelines for secondary prevention of coronary heart disease in post-acute coronary syndromes patients in Kuwait. Plos One. 2020;15:e0241633.

12. Kemar D, İşler Dalgıç A. Evidence-Based Nonpharmacological Nursing Practices Used in Pain Management in Newborns. BAUN Health Sci J. 2020;9:197-204. Available online at: https://dergipark.org.tr/tr/pub/ balikesirsbd 
13. Nydahl P, Egerod I, Hosey MM, Needham DM, Jones C, Bienvenu OJ. Report on the Third International Intensive Care Unit Diary Conference. Crit Care Nurse. 2020;40:e18-e25.

14. Kia Z, Allahbakhshian M, Ilkhani M, Nasiri M, Allahbakhshian A. Nurses' use of non-pharmacological pain management methods in intensive care units: A descriptive cross-sectional study. Complement Ther Med. 2021;58:102705.

15. Hunter OO, Pharm AW, Leng J, Mariano ER. Educating Nurses on Intravenous Lidocaine for Postoperative Pain Management. Pain Manag Nurs. 2021;22:94-9.

16. Tano PF, Apiribu F, Tano EK, Boamah Mensah AB, Dzomeku VM, Boateng I. Predicting factors that determine patients' satisfaction with postoperative pain management following abdominal surgeries at Komfo Anokye Teaching Hospital, Kumasi, Ghana. PLos One. 2021;16:e0251979.

17. Campbell E. Faculty perspectives of teaching pain management to nursing students. Pain Manag Nurs. 2020;21:179-86.
18. Laekeman M, Schäfer A, Moog ME, Kuss K. Recommendations for a Pediatric Pain Education Curriculum for Physical and Occupational Therapists: Scoping Review and Survey. Children. 2021;8:390.

19. Chatchumni M, Eriksson H, Monir Mazaher A. Scoping Review of Pain Management Education Programs (PMEPs): Do They Prepare Nurses to Deal with Patients' Postoperative Pain? Hindawi Pain Research and Management. 2020;1-7.

20. Maestro-Gonzalez A, Mosteiro-Diaz P, Fernandez-Garrido J, Zuazua-Rico D. Determinants of Knowledge of Pain among Nurses in a Tertiary Hospital in Spain. Pain Management Nursing. 2021;22:394-401.

21. Erzincanli S, Sayin Kasar K. Effect of Hand Massage on Pain, Anxiety, and Vital Signs in Patients Before Venipuncture Procedure: A Randomized Controlled Trial. Pain Management Nursing. 2021;22:356-60. 